\title{
LA DIMENSIÓN SOCIAL DE LA SUSTENTABILIDAD EN SISTEMAS HIDROAGRÍCOLAS
}

\author{
Davison Mazabel y Manuel Romero. \\ Con la colaboración de Miguel A. Hurtado. \\ Universidad de Guanajuato. \\ Campus Guanajuato, México, 2010.
}

\author{
ISAÍAS TOBASURA ACUÑA ${ }^{1}$
}

isaias.tobasura@ucaldas.edu.co

Manizales, 2011-04-08 (Rev. 2011-05-08)

\begin{abstract}
La obra objeto de esta reseña, fue publicada por la Universidad de Guanajuato, División de Ciencias Sociales y Humanidades, en el año 2010. Sus autores son los profesores Davison Mazabel y Manuel Romero, Doctorados en Antropología en la Universidad Nacional Autónoma de México (UNAM) y Física, respectivamente. Actualmente, profesores de la Universidad de Guanajuato. Además, colaboró en la misma, el Licenciado en Desarrollo Territorial, Miguel A. Hurtado, actualmente asesor del Gobierno Municipal de Santiago Maravatío, Guanajuato. El libro presenta los principales resultados de dos estudios comparativos en el municipio de Tarandacuao (Guanajuato), México, en sistemas de riego de dos comunidades.
\end{abstract}

El libro tiene como propósito presentar los principales resultados obtenidos en la evaluación de la sostenibilidad de dos sistemas de riego, desde una perspectiva social. Para ello, los autores utilizan un sistema de evaluación apoyado en la metodología MESMIS, Marco para la Evaluación de Sistemas de Manejo de Recursos Naturales incorporando Indicadores de Sustentabilidad, adaptado de un estudio realizado por González et al., en sistemas lecheros de México. Está dirigida al público interesado en los temas ambientales, en el ámbito rural y la sustentabilidad de los sistemas productivos. El texto busca ofrecer una presentación conceptual muy concisa acerca de la sustentabilidad social y presentar los resultados de un estudio preliminar de evaluación, en la búsqueda de indicadores que permitan dar elementos para mejorar la gestión de los sistemas de riego estudiados.

La obra se divide en dos partes: la primera aborda la dimensión social de la sustentabilidad, señalando los principales enfoques y límites. En esta parte, los autores cuestionan los indicadores que se han utilizado para estimar la sustentabilidad, dejando claro que éstos han enfatizado en las dimensiones económica y ambiental y escasamente en la dimensión social. Por ello, insisten en la sustentabilidad social o socio-ambiental en esta investigación. Desde el punto de vista de la organización de la obra, esta parte se puede considerar como el marco teórico de la misma. Presenta un acercamiento al concepto de sustentabilidad, haciendo énfasis en la dimensión social.

En la segunda parte, se presentan los resultados de los estudios realizados en los dos sistemas de riego: uno tradicional, en la Asociación de Usuarios "Ojo de Agua" de Tarandacuao, con 98 propietarios; y el otro, alternativo o modificado, en el ejido de San José de Porto, con 90 ejidatarios. En esta parte, los autores explican la metodología utilizada, los indicadores seleccionados, los instrumentos y técnicas de recolección de la información, los resultados de la evaluación y las conclusiones y recomendaciones derivadas del estudio.

Los autores han presentado avances de esta investigación, sobre todo de la segunda parte, en diferentes eventos académicos realizados en Colombia y México. Además, han publicado una artículo titulado: "La evaluación social de la sustentabilidad en la agricultura de riego", en la revista Ra Ximhai, sociedad, cultura y desarrollo sustentable, Vol. 6, No. 2, mayo-agosto, de la Universidad Autónoma Indígena de México. El artículo recoge los principales aspectos tratados en el libro, en una versión breve. La referencia a dicho artículo no tiene otro propósito que facilitar a los interesados acceder a los resultados de esta investigación a través de la revista.

La obra tiene como características distintivas dos aspectos fundamentales: el primero, señala la debilidad que ha existido en la construcción de indicadores para determinar la sustentabilidad, sobre todo en la dimensión social. Al respecto señalan que ésta ha estado orientada por dos hipótesis: la del "círculo vicioso", según la cual la pobreza conduce a la degradación ambiental de ecosistemas y el deterioro de los ecosistemas conduce a la pobreza. La segunda, conocida como del "doble camino", según ésta la degradación ambiental puede ser el resultado de la integración al sistema mercantil. Según los autores, tanto en la primera como en la segunda hipótesis, los cambios técnicos para resolver cuestiones ambientales, no significan alteraciones en las relaciones de producción. Se deduce, entonces, que los problemas ambientales son, en principio, originados por las relaciones sociales de producción imperantes en el sistema capitalista. 
De la segunda parte, se destaca la adaptación de los indicadores que hacen los autores para aplicarlos en las dos asociaciones seleccionadas para la evaluación de sistemas de riego. Como anotan los autores, se conocen pocos trabajos utilizando esta metodología a sistemas de riego, y de ahí que este trabajo constituya un aporte pionero. De hecho, los indicadores de sustentabilidad utilizados son cuantitativos o cualitativos, lo que permite "medirlos o describirlos para construir escenarios en donde se pueda percibir el potencial y los límites del sistema evaluado". Ello permite retroalimentar el sistema y proponer estrategias para solucionar los problemas que afectan los ecosistemas.

Como resultado destacable de la evaluación realizada, se puede concluir que el sistema "tradicional" tiene un mayor grado de sustentabilidad que el sistema alternativo o modificado. En aquel, de los 16 indicadores utilizados, seis se ubican en el nivel alto y siete en el nivel medio. En tanto que en el sistema modificado o alternativo, cinco se encuentran en el nivel alto y tres en el nivel medio. De todas formas, después de comparar los indicadores, se concluye que los dos sistemas tienen la posibilidad de permanecer o continuar en el tiempo, tomando medidas para remediar o resolver los principales problemas que los afectan.

Como ya se ha dicho, los autores con esta obra hacen un aporte conceptual y metodológico para determinar la sustentabilidad de sistemas socio-productivos, en un aspecto en lo que aún hay muchos vacíos en la definición y el uso de indicadores. No obstante, se debe señalar que la conceptualización sobre la sustentabilidad sigue quedándose corta para efectos de precisar los alcances y limitaciones del concepto. Si bien los autores sitúan el debate sobre la sustentabilidad en la crisis de la modernidad y de su consecuente proyecto de desarrollo modernizador, en su etapa neoliberal como modelo único, se quedan cortos a la hora de avanzar en la construcción de un concepto de sustentabilidad que exorcice los demonios del proyecto civilizatorio y no solo del modelo capitalista de producción, porque no solo el capitalismo, con sus relaciones de producción, destruye los recursos naturales y afecta la sustentabilidad de los sistemas sociales, sino también del capitalismo de Estado, como ocurrió en muchos países socialistas.

Es más: con respecto a la sustentabilidad, desde la óptica de la Economía Ecológica se han propuesto dos versiones de la sustentabilidad: la una, en sentido "débil", en la que la sustentabilidad se garantiza manteniendo el "stock de capital" de la sociedad, donde el capital construido por los seres humanos puede reemplazar el "capital natural", lo cual se constituye en una falacia. Por ello, se ha propuesto la sustentabilidad "fuerte", donde el capital natural no puede ser sustituido por capital construido por los seres humanos. La concepción de sustentabilidad considerada es fundamental a la hora de diseñar los indicadores. Al igual que ha sucedido con los indicadores sobre medición de la pobreza, se puede decir en este caso, que hay más indicadores que conceptos que orienten su construcción.

Por su parte, en el caso de los indicadores no hay duda de que los autores hacen un esfuerzo valioso para adaptar indicadores que permitan evaluar la sustentabilidad, en la dimensión social, que es donde hay menos avances. Sin embargo, y sin cuestionar la pertinencia y validez de los indicadores seleccionados, se puede cuestionar, por una parte, la manera como se obtiene la información. Los autores evalúan mediante entrevistas a actores internos (usuarios de los sistemas de riego) y externos (investigadores), con base en las percepciones que dichos actores tienen sobre los indicadores seleccionados. No obstante, la intención de dar participación a los usuarios y a otros actores, hay aspectos de la sustentabilidad que no se pueden evaluar solo con la percepción.

Por otra parte, si no se evalúan las dimensiones económica y ambiental de la sustentabilidad, no se podría concluir de ninguna manera que la sustentabilidad del sistema de manejo de los recursos naturales, en este caso del agua, está garantizada, porque la sustentabilidad debe analizarse en su real magnitud y complejidad. De lo contrario, se llegaría a afirmar que los dos sistemas son sustentables socialmente en el tiempo $i$ ?, es decir, en su gestión, pero podría estar afectándose el ecosistema, con lo que se podría llegar a un escenario como el de tener un sistema social de gestión de los sistemas de riego sustentables, pero estar agotando o destruyendo los recursos.

En fin, hay muchos elementos para el debate que podrían discutirse. Por ello, se invita a los interesados en el debate conceptual y metodológico sobre la sustentabilidad en el manejo de recursos en contextos rurales a consultar el libro objeto de esta reseña.

1. Doctor en Sociología del Medio Ambiente. Profesor de la Universidad de Caldas, Manizales, Colombia. 